\title{
A ORATÓRIA EPIDÍTICA NA GRÉCIA ANTIGA: O EVÁGORAS DE ISÓCRATES
}

\author{
ÍSIS BORGES BELCHIOR DA FONSECA* \\ Faculdade de Filosofia, Letras e Ciências Humanas \\ da Universidade de São Paulo
}

\begin{abstract}
RESUMO: Neste artigo, rememoramos primeiramente o início da Retórica grega e sua divulgação pelos sofistas; em seguida, após ter mostrado Isócrates na qualidade de retor e de educador, abordamos por fim o tema principal: Isócrates, o homem político. Considerado como o maior representante do gênero epidítico, ele preocupa-se com a situação política da Grécia, como o comprovam alguns de seus discursos, particularmente o Evágoras, em que faz o elogio do rei de Chipre, ilha importante por sua posição estratégica, nas proximidades de regiões sob o domínio persa.
\end{abstract}

PALAVRAS-CHAVE : gênero epidítico; Isócrates; retor; educador; político; Chipre; Evágoras; elogio; oração fúnebre.

Para bem compreender o desempenho de Isócrates, discípulo de sofistas, em sua função de mestre de retórica e educador, na Grécia do século IV a. C., é de interesse rememorar certas referências ao desenvolvimento dessa arte, que teve seu início em Siracusa, em 465 a. C., e foi divulgada na Grécia por intermédio de sofistas. Defendiase aí uma retórica com base na demonstração técnica do verossímil, que era considerado mais estimável que o verdadeiro. Considerava-se a importância do exercício no ataque ou na defesa de uma mesma tese, no intuito de adquirir mais recursos para bem desenvolver uma argumentação.

Protágoras, o mais antigo dos sofistas, foi o primeiro a trazer efetivamente a retórica siciliana para a Grécia. De maneira geral, os sofistas tinham o maior interesse pelo ensino da retórica, procurando criar a persuasão por argumentos especiosos, mas não deixavam de mostrar certa curiosidade no que concerne à moral e à filosofia. No âmbito do ensino, entretanto, já sobreleva a grande diferença de sua atitude com a dos socráticos, porquanto estes se preocupavam com a pesquisa que tenciona fazer chegar a proposições morais de uma verdade universal. 
Protágoras, autor de obras filosóficas, deixou uma célebre fórmula: "O homem é a medida de todas as coisas, das que são enquanto são, das que não são enquanto não são", Essas posições, interpretadas das mais diversas maneiras, já eram vistas pelos antigos como uma afirmação de relativismo gnosiológico considerado perigoso, porquanto se prestava a aplicações em outros campos, como o ético e o político.

Como os sofistas afirmavam que, sobre qualquer argumento, há dois discursos que se contrapõem e que eles podem converter em mais forte a causa mais fraca, essa declaração pode ser entendida como uma indiferença moral e provocar o descrédito que envolveu os sofistas daquela época e os posteriores.

O sofista Górgias estabeleceu o vínculo entre a retórica da Magna Grécia e a da Grécia continental. Discípulo do filósofo siciliano Empédocles, revelou aos atenienses uma prosa que obtinha os mesmos efeitos da poesia, no que tange à sedução e à persuasão atraente e absorvente. Com a introdução do ritmo, do uso de termos da linguagem poética e de figuras retóricas, a prosa de Górgias ganhou maior força e beleza. Além da eloqüência como persuasão, esse sofista adotou em sua doutrina o conceito de poesia como apáte, isto é, engano, ilusão, sedução. Esse conceito certamente foi tomado da educação pitagórica recebida de Empédocles, mas enquanto os adeptos do pitagorismo se preocupavam em curar o corpo e a alma, o que importava para Górgias era o admirável desvio operado pela palavra poética, ou para obter uma cura ou para provocar uma agradável doença. O conceito de apáte da doutrina gorgiana aparece diferente daquele da poesia, visto que nesta se crê em coisas que não existem, enquanto naquela, por efeito da persuasão retórica, as coisas se tornam diferentes do que na realidade são, de acordo com os propósitos do orador.

Os conceitos da apáte e da peithó retórica estão arraigados na idéia da força psicagógica do lógos, isto é, em sua força de sedução irracional.

Falando-se de Górgias, não se pode deixar de trazer à memória a linguagem antitética de que foi o mestre, linguagem essa caracterizada pelo paralelismo ou pela oposição de idéias, na correspondência de formas.

Depois dessas breves e indispensáveis referências ao trabalho dos sofistas no campo da retórica, pode-se situar no desenvolvimento dessa arte o grande mestre de Atenas, Isócrates, discípulo de sofistas, como Pródico, e também Górgias, cujos cursos pôde seguir na Tessália. Diz-se que deve ter tido a oportunidade de seguir os ensinamentos de Sócrates.

Retornando da Tessália para Atenas, por volta de 400 a. C., Isócrates viu-se forçado, por dificuldades financeiras, a trabalhar como logógrafo, isto é, dispôs-se a escrever discursos para litigantes. Como alimentava outros planos para o exercício de 
sua profissão, abriu uma escola, em 393 a. C., de onde saíram formados oradores, historiadores, trágicos e estadistas.

Desinteressado da eloquência judiciária, seu objetivo era tornar-se mestre de retórica e conselheiro político. Pouco se conhece das técnicas que ele aplicava no ensino, mas a composição retórica era o exercício fundamental. Os estudantes deviam ter, em primeiro lugar, uma aptidão natural, que depois então seria desenvolvida pela prática e teoria (Kennedy, 1963, p. 178). Em sua concepção, a eloqüência é uma cultura completa, designada por ele como filosofia, que tem o sentido amplo de cultura intelectual e não o de retórica. Opõe-se, pois, à filosofia platônica, porquanto não admite estudos puramente especulativos. Discordando totalmente de Platão na concepção da vida e nas idéias sobre a formação do espírito, Isócrates contudo alia-se a ele na crítica aos sofistas.

Deve-se observar, no que concerne a Górgias, que, se para esse sofista era preciso que a palavra apenas criasse persuasão e psicagogia, para Isócrates ela devia sobretudo produzir sabedoria e, assim, a função da retórica deixava de ter seu apoio numa força irracional e era vista como um método de educação racional, visando a que os homens se tornassem bons e sensatos. (cf. Isócrates, Sobre a permuta, 220). Considerando que a eloqüência era um meio de formar a alma na virtude, ela não se descuidava de desenvolver grandes temas, expostos em forma elaborada a ponto de torná-las semelhantes a criações poéticas.

Isócrates condenava o orador sem convicção profunda e apenas interessado em exibir suas habilidades na eloqüência, como habitualmente acontecia com os sofistas, que proclamavam conhecer os meios infalíveis de tornar eloqüente qualquer indivíduo.

A obra de Isócrates revela-nos o mais importante autor de discursos do gênero epidítico ou demonstrativo da Grécia Clássica. Ele não poderia ser um orador do gênero deliberativo, em virtude da debilidade de sua voz e de sua timidez, deficiências que dificultavam sua apresentação em público. Essa referência ao gênero epidítico levanos a relembrar suas características. De maneira geral, esse gênero visa ao louvor e à censura, servindo-se dos tópicos do belo e do feio. Quanto ao ouvinte, é apenas espectador e só tem que se pronunciar sobre a faculdade oratória. $\mathrm{O}$ tempo próprio deste gênero é o presente, porque para louvar ou para censurar nos apoiamos sempre no estado presente das coisas; contudo, sucede que freqüentemente utilizamos a lembrança do passado ou presumimos o futuro (cf. Aristóteles, Retórica , I, 3).

O maior mérito de Isócrates está na criação de um estilo literário que, através de Cícero, chegou até nós, servindo de modelo para a arte posterior. Esse estilo é 
caracterizado pela sábia disposição das frases no período e também pelos períodos amplos, harmoniosamente dispostos.

Depois de destacar o papel de Isócrates como mestre de retórica, é de interesse ressaltar seu empenho na busca de solução para conseguir a união dos gregos contra o inimigo externo. O pensamento político do século IV está voltado para a Grécia como um todo. Essa política pan-helênica é a maior preocupação de Isócrates. Embora essa idéia não fosse nova, ela retornou com a maior força, quando as colônias gregas da Ásia passaram para o domínio persa, com a "paz do rei", em 386. Esse tratado humilhante, negociado pelo espartano Antálcidas, foi assinado por Esparta com a Pérsia.

Isócrates concebe uma confederação grega em que cada cidade-estado conserve sua autonomia interior. É preciso que haja um comando único, uma chefia, mas a quem se deve atribuir essa função? A resposta a essa indagação vai sujeitar-se a mudanças, conforme as circunstâncias do momento. Assim, inicialmente é em Atenas que Isócrates vê a solução de seu problema, porquanto ela merece esse destaque por sua alta dignidade mística e histórica. Nesse ínterim, Isócrates, como mestre de retórica, sentiu que podia ampliar seu campo de influência, levando para além de seu âmbito de ensino suas opiniões sobre a política do país. Para isso serviu-se do discurso fictício que surgira nas escolas dos sofistas e dos mestres de retórica, atravessando os séculos como exercício de composição literária. Em fins do século V, esse tipo de peça oratória já tinha sido utilizado para a propaganda política. Sua grande vantagem estava no fato de permitir maior concentração de atenção nas idéias essenciais do tema que o orador se propunha desenvolver, porquanto eliminava a preocupação natural com as contingências peculiares de uma assembléia pública.

As grandes festas religiosas, as panegírias, ofereciam ao talento e aos hábitos de Isócrates a oportunidade ideal para a divulgação de suas opiniões a respeito da situação política da Grécia, em determinado momento.

Atendendo à sua maior preocupação, ele instiga os gregos a se aliarem contra a Pérsia, sob o comando de Atenas, altamente qualificada por sua superioridade de cultura, pelos serviços já prestados à nação no confronto com as forças persas e pela relativa brandura de seu domínio sobre a Grécia. Era necessário apenas que essa brandura fosse ainda maior e que sua hegemonia revelasse maior respeito aos direitos dos aliados. No discurso fictício Panegírico, de 380, o orador, dirigindo-se aos gregos reunidos em Olímpia, expõe magistralmente sua tese. Como título desta peça oratória foi tomado o adjetivo panegyricós, formado sobre o substantivo panégyris, que significa assembléia geral,assembléia de todo o povo. Panegyricós, acompanhado ou não de lógos, discurso, é aquele pronunciado numa assembléia geral, numa festa pública, numa 
panegíria, portanto. Julga-se que talvez por influência do Panegírico se tenha formado a Segunda Confederação de Atenas, em 377 a. C.. Após o período de hegemonia de Esparta, Atenas alia-se a Tebas, organizando essa nova confederação marítima, a fim de combater Esparta ${ }^{1}$.

Com os erros cometidos posteriormente por Atenas, e ainda com os desentendimentos entre as mais poderosas cidades - Atenas, Esparta e Tebas - Isócrates, no intuito de achar um aliado ao seu grande plano de união de forças para o combate ao inimigo externo, volta sua atenção para chefes de governos em que esperava encontrar o interesse efetivo pela causa comum da Grécia. Nessa nova etapa do desenvolvimento político de Isócrates, suas esperanças convergem para Jasão, tirano de Feras na Tessália, Arquidamo, filho do rei de Esparta, os príncipes cipriotas, Evágoras e Nícocles, e, mais tarde, ainda Filipe da Macedônia, após a paz de Filócrates, de $346^{2}$.

No que concerne à expectativa de obtenção de apoio de Chipre - importante pela posição dessa ilha nas proximidades das terras de domínio persa, - Isócrates deve ter considerado de grande interesse manter amizades nos domínios mediterrâneos do Grande Rei, mesmo que não visse, nesses príncipes, possíveis chefes da coligação grega. Ele realmente já tinha enviado a esses amigos epístolas e exortações. Pertencem ao grupo dessas exortações (parainéseis) discursos dirigidos a grandes personalidades com abundantes reflexões de ordem moral, que traduzem a preocupação constante desse mestre de retórica, como educador. Citam-se o A Nícocles, cujo tema são os deveres de um rei e o Nícocles, que desenvolve o tema sobre os deveres dos súditos.

Na história, há poucas referências a Nícocles, filho de Evágoras, que Isócrates apresenta como descendente de Teucro, o famoso arqueiro citado na Ilíada. Não se sabe por quanto tempo Nícocles reinou em Salamina, cidade de Chipre, sucedendo a seu irmão que, como seu pai, também tinha sido assassinado.

As exortações de Isócrates a Nícocles foram escritas após a morte de Evágoras, que ocorreu em 374 a. C..

Para se avaliar a habilidade de Isócrates na elaboração dessa obra, que representa a primeira tentativa do autor de compor um elogio em prosa, é imprescindível recorrer à Retórica de Aristóteles, que servirá então de apoio às observações que se seguirão.

No proêmio do discurso já se evidenciam as características do gênero epidítico, visto que o objetivo desse gênero é a virtude relacionada com a beleza, e, na retórica, a virtude deve ser considerada como a faculdade de procurar e conservar os bens superiores, e de prestar serviços ao próximo. (cf. A. Reyes, Obras completas, vol. XIII, pp. 226-7). 
Sendo dado que o tópico do belo - tò kalón - é o mais importante nesse gênero, é de interesse observar como Isócrates vai utilizá-lo. Ele parte de uma comparação que estabelece entre o suposto reconhecimento de Evágoras ao filho pela preparação luxuosa e impecável das cerimônias fúnebres a ele dedicadas, e o reconhecimento muito maior que ele teria, se alguém pudesse falar de seus hábitos de vida e dos riscos que enfrentara. Serviu-se, pois, nessa comparação do lugar-comum do mais ou do menos, dito comum por ser usado em qualquer um dos três gêneros do discurso retórico, e ainda por não provir de conhecimentos especiais, de ciências determinadas. Como a matéria do argumento é accessível a todos, o auditório torna-se bem disposto a ouvir com atenção e docilidade o elogio sobre as ações de Evágoras em vida, elogio esse que imortalizará suas virtudes.

Segundo Aristóteles, para captar a atenção do ouvinte cabe ao orador preocupar-se com sua aparência de honestidade, pois é sobretudo a pessoas honestas que se presta atenção. $O$ orador deve já no proêmio tentar assegurar a credibilidade emocional do ouvinte, mostrando-se possuidor de três atributos básicos: sabedoria, virtude e benevolência, elementos que definem o caráter do orador, o éthos.

No início deste discurso, já se evidenciam essas qualidades de Isócrates, quando ele destaca e exalta a importância da virtude na vida do ser humano, não perdendo o ensejo de introduzir sabiamente conselhos aos jovens, É assim que, sempre preocupado com seu papel de educador, justifica sua intenção de enaltecer as virtudes de Evágoras, dizendo que os elogios de grandes homens da época sobre feitos de conhecimento público estimularão os jovens que se tornarão melhores, na esperança de receber um dia elogios mais significativos.

Na seqüência do proêmio, Isócrates, no intuito de enfatizar a argumentação, utiliza a figura de estilo que constitui um expediente dialético, a amplitude, explorando com isso outra fonte do proêmio epidítico: a censura. Condena, então, a inveja dos que não se aprazem em ouvir falar de ações que merecem elogios, esquecendo-se de que os progressos de toda a atividade humana se fazem por esforços de pessoas ousadas.

Antes de concluir o proêmio, Isócrates, nos $\S \S 8$ a 11, procura assegurar-se da benevolência dos ouvintes, concentrando sua atenção na valorização de seu próprio empreendimento: a árdua tarefa de celebrar o mérito de um homem através de palavras, na elaboração de um discurso oratório. Verifica-se facilmente essa dificuldade, diz ele, na comparação com o trabalho de filósofos, que nunca abordaram temas dessa espécie, ou com o dos poetas, que dispôem de abundantes recursos na utilização de ornamentos os mais variados, e, servindo-se de metros e ritmos, seduzem a alma pela harmonia e pela simetria. 
Na conclusão do proêmio, está a idéia de que vale tentar mostrar se a palavra oratória pode celebrar os grandes homens tão dignamente quanto os contos e os versos. É um desafio que Isócrates se propõe, deixando de lado a indicação do plano a seguir na exposição de seu tema, como habitualmente se vê nos proêmios.

A partir do $\S 12$, inicia-se a Narração, que a arte retórica define como "exposição pormenorizada, parcial, encarecedora, do que de modo sintético e direto se expressa na proposiçãa". (cf. H. Lausberg, Manual de Literatura Retórica Literária, tr. esp. 1966, vol. 1 p. 261). Neste discurso, a indicação do assunto a ser tratado, a proposição, aparece não separadamente do proêmio, mas claramente aí incluído.

Como era usual na literatura grega, o autor, no intuito de valorizar o indivíduo, recorria à questão da hereditariedade, da mesma maneira como se servia da tradição quando tencionava enaltecer uma cidade. É assim que Isócrates vai dedicar vários parágrafos (12-18) à origem de Evágoras, apresentando-o como descendente de Éaco, filho de Zeus (e de Egina). De Télamon e Peleu, filhos de Éaco, são descendentes do primeiro Ajax e Teucro, e de Peleu, Aquiles. Vale notar que o parentesco entre Peleu e Télamon é uma tradição pós-homérica. Teucro, considerado o melhor arqueiro do exército grego, na guerra de Tróia, fundou Salamina de Chipre, diz Isócrates, e deu-lhe o nome de sua pátria.

Com essa evocação do passado longínquo de Evágoras, o autor já lhe dá uma posição de destaque entre os simples mortais para então narrar atividades brilhantes que vão notabilizar seu herói e elevá-lo a importante chefe de estado. Partindo da elucidação sobre a situação política de Chipre no momento em que Evágoras se viu solicitado a retomar o poder que fora usurpado à sua família e se encontrava nas mãos do rei da Pérsia, Isócrates dá início a uma longa narração sobre a vida de Evágoras, sempre enaltecendo suas qualidades físicas e morais. Convém notar que os comentários sobre seu caráter e sua conduta são construídos por meio de uma série de antíteses, fazendo lembrar muito o estilo gorgiano. Entre muitas frases assim construídas, podese citar, como exemplo, a seguinte:

Evágoras verificava que "as verdadeiras distrações devem ser procuradas não no lazer, mas no sucesso e na perseverança”.

Há construções em que os dois pensamentos de sentido antagônico não estão ligados imediatamente pela coordenação, mas o primeiro pensamento é amplificado com vários pormenores para então iniciar a expressão do segundo pensamento. Assim, no início do § 9, Isócrates diz: "Os poetas dispõem de numerosos processos de ornamento". Introduz a seguir uma série deles, antes de dizer, no início do § 10: mas os oradores, ao contrário, não dispõem de nenhuma dessas facilidades. 
No que tange aos superlativos, vale ressaltar seu uso abundante, denotando o intuito evidente do autor de intensificar suas afirmações, e, quando não as emprega, constrói frases que correspondem a esse objetivo, o de elevar ao máximo cada declaração. Assim, lê-se no § 43: "Ele viveu a sua vida toda sem cometer injustiça contra ninguém, honrando os honestos, exercendo firmemente sua autoridade sobre todos, punindo os culpados de acordo com as leis".

Na leitura da narração deste discurso, verificam-se claramente as observações de Aristóteles; "a narração no gênero epidítico não é contínua, mas dividida em muitas partes: é mister expor pormenorizadamente os atos que formam o fundo do discurso".

Isócrates, realmente, com grande habilidade destaca os fatos que darão força à Argumentação que pretende desenvolver. No que concerne a esta parte do discurso, ela constitui sem dúvida "a parte nuclear e decisiva, e vem já preparada pelo proêmio e pela narração" (cf. Lausberg, op. cit., p. 297).

As fontes de argumentação são o silogismo retórico, ou entimema, figura de dedução retórica, e o exemplo, figura de indução retórica.

As proposições do entimema, se necessárias têm o apoio da dialética, mas habitualmente são apenas prováveis, verossímeis, freqüentes, e é este o campo exclusivo da retórica (cf. A. Reyes, op. cit., p.221).

Entimemas e exemplos constituem as chamadas provas técnicas objetivas da retórica, que são intelectuais, lógicas, enquanto provas subjetivas são o éthos, o caráter, e o páthos, termo que envolve o mundo todo da irracionalidade emocional.

É de interesse destacar a habilidade do autor em explorar esses dois recursos retóricos.

Em discurso do gênero epidítico, apresentam-se numerosas situações e comportamentos, que, tornados conhecidos, servirão de exemplos na orientação da melhor atitude a tomar em determinadas circunstâncias. É bem isso que se vê neste discurso em foco, no $§ 62$.

Isócrates relata que Evágoras, forçado a guerrear, quase tomou Chipre inteira, devastou a Fócida, tomou Tiro, separou a Cilícia do Grande Rei etc.. Por esse exemplo, os reis, contrariando seus hábitos, regozijaram-se em fazer a paz com ele, continua Isócrates, sem tocar em sua autoridade.

Estabelecida, então, a relação do particular conhecido ao particular menos conhecido, tem-se o exemplo, ou paradigma, segundo a definição da retórica.

Para citar mais um exemplo, convém observar os $\$ \S 47$ a 51, em que o autor comenta os notáveis progressos de Salamina de Chipre, por obra de Evágoras, que a 
encontrou entregue à barbárie, sob influência da soberania fenícia. Numerosos cidadãos gregos, conhecedores de suas atividades, de seus costumes e respeito aos deuses, deixaram sua pátria para habitar Chipre, cuja realeza viam como "mais leve a suportar e mais de acordo com as leis do que as constituições políticas de suas terras".

Em discursos do gênero epidítico, é mais comum o emprego de exemplos do que de entimemas, mas não se poderia deixar de destacar a mestria de Isócrates no emprego desse recurso retórico de menor ocorrência, no qual sobreleva a finalidade permanente de elogiar seu herói. Diz ele, no $§ 59$ e no início do $\$ 60$, que o "Grande Rei sabia que muitos gregos e bárbaros tinham edificado grandes impérios, partindo de uma situação baixa e medíocre". E, continuando, acrescenta: "e via o aumento considerável da glória de Evágoras e de sua posição política". Isócrates então conclui: "ele não se irritava com o passado, mas tremia pelo futuro".

Vê-se que o autor, partindo do geral, na referência que faz a gregos e bárbaros, dirige a seguir a atenção para o particular, quando se refere a Evágoras, concluindo então que o futuro é causa de temor para o Grande Rei.

No exame desse entimema, ficam evidentes as duas premissas e a conclusão, constituindo, assim, um entimema extenso, já que apresenta a premissa maior, a menor, e a conclusão. Por sua natureza, ele é verdadeiro, e, pelo sentido, declarativo. Além disso, deve-se observar que utiliza lugares comuns e não específicos.

Convém ressaltar que, após a narração e a argumentação, este discurso apresenta, em apenas quatro parágrafos, as características próprias de um epílogo. Verificase, de início, que Isócrates, visando a enfatizar a argumentação, serve-se da amplificação, figura de estilo que consiste no alargamento da idéia ou proposição. De fato, retomando a questão da nobreza da família de Evágoras, exposta pormenorizadamente ao tratar de sua origem ( $\S 12-17)$, estende seus comentários para tratar de seus descendentes, todos ele nobres, portadores de títulos ou de rei, ou de príncipes e princesas. O brilho das atividades políticas de Evágoras reflete significativamente a dignidade de sua estirpe. Há um outro ponto importante a ser considerado na elaboração do epílogo, segundo Aristóteles. O orador deve procurar bem dispor o ouvinte em seu favor. É precisamente isso que se vê, quando Isócrates se desculpa por não ter feito um "elogio mais minucioso e mais caloroso", em virtude de sua idade. De fato, ele devia ter, então, cerca de setenta anos.

Quanto à recapitulação, que habitualmente se faz no epílogo, Isócrates retoma sua opinião, manifesta no início de seu discurso, sobre a superioridade de uma homenagem que celebra as qualidades de espírito e as ações em comparação com as homenagens de caráter material. Foi apoiado nessa reflexão que Isócrates constituiu a longa 
exposição sobre o elogio de Evágoras, acrescentando ainda que a palavra, em oposição à homenagem material, apresenta a vantagem de poder ser divulgada através de toda a Grécia.

A última parte do discurso Evágoras é constituída pela Exortação, que se inicia no $§ 76$. Isócrates conclama Nícocles, seus filhos e todos os descendentes a observar e a praticar as virtudes de Evágoras. Todos devem procurar imitar o espírito de grandes homens e, assim, adquirir as virtudes tão elogiadas do soberano de Chipre.

Em todo esse desenvolvimento, Isócrates adota a teoria segundo a qual a virtude pode ser ensinada e mesmo reproduzida por imitação. Esse princípio socrático é contestado em outros discursos do mesmo autor, como se vê em Sobre os Sofistas, e Sobre a Permuta.

Para finalizar ( $\$ \S 80-81$ ), o autor dirige conselhos e exortações a Nícocles, incitando-o a nada negligenciar e a tentar constantemente superar os demais, como descendente longínquo de Zeus e filho de um homem da alta qualidade de Evágoras.

Examinadas as partes que constituem o discurso Evágoras, sem dúvida podem ser eliminadas as hesitações, que a crítica já manifestou na Antigüidade, sobre se essa peça oratória devia ser incluída entre os elogios ou entre as orações fúnebres. Como se sabe, estas apresentam partes claramente definidas e habitualmente respeitadas por seus autores. Com a falta de duas delas, a das condolências e a das lamentações, já se exclui a possibilidade de caracterizar o Evágoras como oração fúnebre.

Esse discurso, dirigido a Nícocles, parece ter sido redigido em 365, vários anos, portanto, após a morte de Evágoras, datada de 374/3. Diante desses dados, é evidente que Isócrates não poderia incluir, na composição de seu discurso, a parte das lamentações pelo falecimento do soberano, e, portanto, já ficava excluída a parte subseqüente das condolências. De fato, sem ter lamentado a morte do rei, como consolar os parentes do finado?

Este discurso, definido, então, claramente como um elogio, e não como oração fúnebre, é desenvolvido de tal maneira que reclama de seu autor, como coroamento de sua obra, a exortação em que, ressaltando sua preocupação de educador, aconselha e incita Nícocles a se manter sempre digno dos antepassados, e a observar e praticar as virtudes de seu pai, tomando-o como exemplo.

\section{Notas}

* Professora Doutora de Língua e Literatura Grega do Programa de Pós-Graduação em Letras Clássicas da FFLCH-USP. 
1 Depois das guerras médicas, Aristides, de volta a Atenas, organiza em 477 a. C., a Confederação Marítima, que reúne a maioria das ilhas do mar Egeu e das cidades jônicas, como aliadas e protegidas de Atenas.

2 A Paz de Filócrates foi concluída entre os atenienses e Filipe II da Macedônia, depois que este rei tomou Olinto, tornando-se senhor da Calcídica.

\section{REFERÊNCIAS BibliográFICAS}

ARISTOTE. Rhétorique I-II. Paris, Les Belles Lettres, 1967.

ISOCRATE. Evagoras. Paris, Les Belles Lettres, 1967.

KENNEDY, G. The Art of Persuasion in Greece. London, Routledge and Kegan, 1963.

LAUSBERG, H. Manual de retórica literária. Madrid, Gredos, 1966.

NAVARRE, O. Essai sur la rhétorique grecque avant Aristote. Paris, Hachette, 1900.

PLEBE, A. Breve história da retórica antiga. Trad. brasileira. São Paulo, EPU/EDUSP, 1978.

REYES, A. Obras completas, vol. XIII. México, Fondo de Cultura Económica, 1961.

WORTHINGTON, I. Persuasion: Greek Rhetoric in Action. London and New York, Routledge, 1993.

FONSECA, Ísis Borges Belchior da. Loratoire épidictique dans la Grèce ancienne: l'Evagoras d'Isocrate.

RÉSUMÉ: Dans cet article, tout d'abord, nous évoquons les débuts de la Rhétorique grecque et sa divulgation par les sophistes; ensuite, après avoir montré Isocrate em tant que maître de rhétorique et d'éducateur, nous abordons enfin le thème principal: Isocrate, l'homme politique. Considéré comme le plus important représentant du genre épidictique, il s'inquiète de la situation politique de la Grèce, comme le prouvent certains de ses discours notamment le Evagoras, où il fait l'éloge du roi du Chypre, île importante par sa position stratégique, à proximité de regions sous la domination perse.

MOTS-CLEFS: genre épidictique; Isocrate; maître de rhétorique; éducateur; homme politique; Chypre; Evagoras; éloge; oraison funèbre. 